\title{
La comunicación en los equipos de atención médica: un desafío esencial para mejorar la seguridad del paciente
} Communication among health care teams: a major challenge for the improvement of patient safety

Los avances en seguridad del paciente son lentos a pesar de los esfuerzos que se realizan en muchos países. Múltiples obstáculos se enfrentan para lograr los cambios que lleven hacia una nueva cultura donde el cuidado seguro de los pacientes sea prioridad en la medicina. Entre ellos, surge el escaso compromiso de los líderes, abordaje inadecuado para evaluar eficientemente los factores que generen daño al paciente y analizar correctamente las causas de los errores. Lograr implementar estrategias que mitiguen los eventos adversos solo se alcanzará trabajando sin pausa y ordenadamente con fuerte apoyo institucional. El desarrollo de habilidades y compromiso de un reducido grupo de profesionales en comités hospitalarios ya no es suficiente y todos los líderes de una institución médica deben estar comprometidos.

Otras estrategias para mejorar, incluyen cambios en la educación de los profesionales de la salud, participación del paciente en su propio cuidado, transparencia, coordinación de la atención y una motivación "moral" en los profesionales. Este requisito implica que nuestras actitudes responsables para evitar perjuicios en los pacientes constituyen un imperativo ético ineludible. Los médicos no estamos obligados a curar pero sí a no producir daño, cualquiera sea.

Asimismo, las notorias dificultades para progresar residen en el propio cuidado de la salud que tradicionalmente se basó en la capacidad y autonomía de los médicos, un enfoque equivocado y difícil de cambiar en forma rápida. Trabajar individualmente, con escasa y deficiente comunicación en un equipo y entre los equipos de una institución médica, es de los impedimentos más nefastos para generar una atención segura.

Un equipose define como "dos o más personas, que tienen funciones específicas, realizan tareas interdependientes, son adaptables y comparten un objetivo común".

Estas características no garantizan que el equipo funcionará efectivamente ya que el trabajo concertado es más que realizar tareas y puede definirse como un "conjunto de conocimientos interrelacionados, habilidades y actitudes que faciliten la actuación coordinada y eficaz" (Baker, et al. 2006). Solo los equipos que contengan estas cualidades podrán compartir lo que desean lograr

La comunicación es un aspecto esencial entre los seres humanos y debería estar presente en forma efectiva en toda actividad que realizan las personas, cualquiera sea. No es entonces extraño que una apropiada comunicación sea reconocida como uno de los factores centrales que sustentan la seguridad y calidad del trabajo en equipos que desempeñan actividades complejas. Esto comenzó a realizarse hace años en industrias de riesgo para incrementar al máximo la seguridad. Probablemente, la aviación comercial sea el ejemplo paradigmático al reducir marcadamente los accidentes y convertirse en una actividad que planifica los mínimos detalles teniendo en cuenta que indefectiblemente las personas se van a equivocar y que, por lo tanto, los sistemas deben prevenir los errores, o detectarlos rápidamente para corregirlos.

Es claro que sin una comunicación eficaz, aun las personas competentes pueden formar parte de un equipo incompetente, tal como sucedió en la trágica explosión de la Central Atómica de Chernoville. El análisis posterior de las causas del accidente detectó entre los principales motivos, la inadecuada o casi inexistente comunicación entre los equipos claves.

Los progresos hacia una adecuada comunicación, en y entre los equipos, aún no han ocurrido en la medicina en magnitud destacable y lamentablemente persiste una comunicación ineficiente entre los profesionales y con el personal administrativo. Este aspecto puede explicar por qué a pesar de los grandes esfuerzos para mejorar la seguridad del paciente, los avances sean limitados.

Sin duda, el ineficaz trabajo en equipo genera perjuicios al paciente. Una revisión de más de 3500 eventos centinela (provocan la muerte o daño grave), realizada por la Joint Comisión de EE.UU. (2004) determinó que el 60\% de la muertes y $50 \%$ de los daños graves se debieron a un fracaso en la comunicación del trabajo en equipo.

Ante esta crítica situación, es auspicioso que dentro del arduo camino que la medicina emprende para generar un cambio de cultura en el abordaje del error, se hayan realizado los 
primeros intentos de investigar la comunicación de los equipos y la seguridad del paciente.

Aun así, aspectos más complicados de la comunicación son poco explorados y las investigaciones no pueden pecar de una simplificación excesiva, siendo que es un proceso extremadamente complejo. Recientemente, recibieron mayor atención los conocimientos técnicos de la comunicación humana, que ayudarán a instalar una "comunicación efectiva" en las instituciones médicas. Abordaré brevemente solo algunos puntos para poder definir mejor la complejidad de este tema.

Lingard L. (Healthcare Quarterly, April 2012) describió los tres aspectos que a su criterio eran promisorios para aportar conocimientos al proceso de comunicación. Ellos son: el significado del silencio, la adopción de innovaciones en comunicación y el fenómeno de la intertextualidad. Hasta hace poco, la investigación en la comunicación se basó en la presencia de la palabra, lo que los miembros del equipo se decían, o deberían estar diciéndose, en su trabajo clínico. El silencio recibió poca atención, aun cuando la importancia de este aspecto es evidente para cualquiera que haya integrado equipos de salud en el trabajo. Sin duda "hay mucho más que se comunica en los equipos que lo que se dijo. La relación entre los miembros está llena de silencios significativos" (Lingard L.).

Inicialmente, los estudios del silencio exploraron por qué los miembros del equipo no pueden "hablar" durante o después de situaciones clínicas peligrosas. En la evaluación de los reportes de errores, se demostró que esto ocurría por la inadecuada cultura de seguridad institucional que motivaban a los profesionales a mantenerse en silencio por temor a represalias. Esto debilita el sistema de reporte y hace que mayormente se informen errores leves o moderados.

Sin embargo, no todo el silencio es problemático y estudiosos en comunicación lo reconocen como un adecuado recurso. Para que sea así, debemos tener en cuenta que no es igual "estar en silencio" que "ser silenciado ", el primero puede suponer un entendimiento que no requiere ser expresado, el segundo puede implicar una restricción. Un ejemplo de esto último podría ocurrir en la confección del listado de seguridad quirúrgica en quirófano. Gardezi, et al (2009) describieron tres formas de silencios en esa práctica: no compartir información, no responder las peticiones y hablar en voz muy baja; y encontró que estas conductas podrían señalar que las personas estaban a la defensiva y el silencio era una estrategia para no comprometerse. Un análisis de errores en cirugía (Christian C, et al. Surgery 2006) reveló que la falta de comunicación fue el factor causal más importante.

El segundo aspecto, la adopción de innovaciones de comunicación, se refiere a varias estrategias para mejorar la comunicación en situaciones especiales, como la ya señalada lista de verificación quirúrgica, procesos de transición (ingreso al hospital, traslado a otra unidad y alta hospitalaria), "pases de sala", "pases de guardia" y cambios del turno de enfermería. Estas situaciones son proclives para que ocurra una alta tasa de errores debida a una inadecuada comunicación. Es largo describir las posibles estrategias a implementar, pero fundamentalmente se orientan a detectar y corregir las debilidades de la comunicación (ver artículo de Belziti y col., página 119).

El tercer aspecto, el fenómeno de la intertextualidad, pretende ir más allá de cómo se transmite la información entre los miembros de un equipo en forma oral, investigando de que forma las prácticas de comunicación afectan a unos y otros. La intertextualidad es utilizada en otras disciplinas para aprender a comprender mejor lo que se hace y es de mucha ayuda para detectar las falencias que ocurren. Es ampliamente conocido que en la práctica médica la información puede llegar distorsionada al pasar de uno a otro ante una comunicación inadecuada. El mayor riesgo es que eso suele ser inadvertido y entonces se crea un terreno fértil para que los errores ocurran. Una apropiada y continua evaluación de los sistemas de comunicación de los equipos, es imprescindible para mejorar la seguridad. Esto nos permitirá conocer como las prácticas de comunicación influyen cuando se produce un error y detectar donde están la fallas para evitar el potencial "efecto dominó" que genere más errores.

Finalmente, quiero enfatizar que en la gran mayoría de los procesos de comunicación estamos los médicos presentes y es innegable que aun mantenemos un mayor poder, aunque esto pueda ser pernicioso. Por tal motivo, no se va a lograr progreso alguno, si nosotros los médicos no somos los primeros en generar y promover una adecuada comunicación en los equipos que integramos. El compromiso en este desafío es imprescindible y debemos tener muy en cuenta que no habrá cambios sustanciales en la seguridad de la atención clínica sin nuestra plena participación. Solo así podremos evitar o mitigar el daño a los pacientes.

José M. Ceriani Cernadas Editor 